\title{
Sphaeropsis sapinea Morphotypes Differ in Aggressiveness, but Both Infect Nonwounded Red or Jack Pines
}

\author{
J. T. Blodgett, Graduate Research Assistant, and G. R. Stanosz, Assistant Professor, Department of Plant Pathol- \\ ogy, University of Wisconsin-Madison, 1630 Linden Drive, Madison 53706-1598
}

\begin{abstract}
Blodgett, J. T., and Stanosz, G. R. 1997. Sphaeropsis sapinea morphotypes differ in aggressiveness, but both infect nonwounded red or jack pines. Plant Dis. 81:143-147.

Two morphotypes of Sphaeropsis sapinea, designated A and B, are recognized in the north central United States. Nonwounded seedlings of red (Pinus resinosa) and jack pine (P. banksiana) were inoculated with conidial suspensions of isolates of each morphotype obtained from hosts in Michigan, Minnesota, and Wisconsin. Wounded seedlings were inoculated with water agar plugs colonized by these isolates. Both morphotypes penetrated both hosts without wounding. On nonwounded seedlings the frequency of symptoms was $97 \%$ for A isolates and $18 \%$ for B isolates on red pine and $42 \%$ for $\mathrm{A}$ isolates and $6 \%$ for B isolates on jack pine. On average, isolates of the A morphotype also were more aggressive than B isolates on wounded seedlings of both pine species (A isolates causing needle necrosis $7.0 \mathrm{~cm}$ from the inoculation sites and B isolates $1.4 \mathrm{~cm}$ ). Based on symptom severity (distance from the inoculation site at which necrotic needles were observed), A isolates could be distinguished from all $\mathrm{B}$ isolates on red pine, but not on jack pine. These observations indicate the potential importance of distinguishing between $S$. sapinea morphotypes encountered in nurseries, plantations, and natural stands.
\end{abstract}

Additional keyword: Diplodia pinea

Sphaeropsis sapinea (Fr.:Fr.) Dyko \& Sutton in Sutton (syn. Diplodia pinea (Desmaz.) J. Kickx fil.) is one of many pathogens of red pine (Pinus resinosa Aiton), jack pine (P. banksiana Lamb.), and other coniferous species (7). It causes shoot blight and cankers that can girdle and kill trees. Extensive damage can occur at all stages of tree development from seedling to timber size. Severe losses of native and exotic conifers due to $S$. sapinea have been reported throughout the world $(8,10,13)$.

Two $S$. sapinea morphotypes, designated $\mathrm{A}$ and $\mathrm{B}$, are recognized in the north central United States (12). Morphotype refers to a group of individuals with unknown or no taxonomic significance within a species, that are morphologically distinguishable (9). The two $S$. sapinea morphotypes differ in colony morphology and growth rates on potato dextrose agar (PDA). Isolates of A morphotype have white to light gray, aerial mycelium and grow more quickly on PDA than B isolates, which have dark gray to black, appressed mycelium (12). Differences in average spore sizes, isozymes (12), and the presence or

Corresponding author: J. T. Blodgett

E-mail address: JTB@PlantPath.Wisc.edu

Accepted for publication 4 October 1996.

Publication no. D-1996-1028-05R

(C) 1997 The American Phytopathological Society abundance of spore surface pits have been reported (20). However, Swart et al. (19) found spore surface pitting to be an inconsistent character. More recently, analyses of random amplified polymorphic DNA markers have allowed differentiation of isolates collected in the north central United States into the currently accepted morphotypes (16).

It has been suggested that morphotypes of $S$. sapinea differ in their requirement for wounds to infect young shoots (12). However, that conclusion was based on examination of only one isolate of each type. In addition, the reported differences in aggressiveness were not statistically significant. In our preliminary study, inoculations of wounded red pine seedlings with two A isolates resulted in more necrotic needles and recovery of $S$. sapinea farther from the inoculation site than inoculations with two $\mathrm{B}$ isolates (1). The objectives of the studies described in this paper were to compare the requirements for wounds to infect hosts and to compare the aggressiveness (relative ability to colonize and cause damage) of $S$. sapinea isolates, using a larger number of isolates and two hosts (red and jack pine). The null hypotheses tested in this study were as follows: (i) morphotypes do not differ in their ability to infect nonwounded seedlings; (ii) morphotypes do not differ in their ability to colonize wounded seedlings; and (iii) neither of the previous hypotheses are influenced by host species. These hypotheses were tested in two greenhouse experiments.

\section{MATERIALS AND METHODS}

Plant material. Dormant, 1-year-old red and jack pine nursery seedlings were lifted 20 May 1994 and transplanted into ConeTainers (conical tubes; width $3.8 \mathrm{~cm} \times$ depth $21.0 \mathrm{~cm}$; Ray Leach, Canby, OR) in a soil mix (vol/vol) of one-half Plainfield sand (containing $89 \%$ sand and $7 \%$ silt) from a 10-year-old red pine plantation in central Wisconsin, and one-half Fafard growing mix No. 2 (Conrad Fafard Inc., Inkerman, NB). Red pine seedlings had a mean stem height of $9.1 \mathrm{~cm} \pm 0.06 \mathrm{stan}-$ dard error (SE) and jack pine had a mean stem height of $11.9 \mathrm{~cm} \pm 0.11 \mathrm{SE}$ at the time transplanted. The seedlings were placed in a greenhouse supplemented with artificial light (maximum recorded ambient greenhouse photon flux density was 1,120 $\mu \mathrm{E} \mathrm{s}^{-1} \mathrm{~m}^{-2}$; supplemented photon flux density averaged $118 \mu \mathrm{E} \mathrm{s}^{-1} \mathrm{~m}^{-2}$ ) to provide a 16-h photoperiod. Seedlings were watered to field capacity every other day. The average greenhouse day temperature was $27.5^{\circ} \mathrm{C} \pm 0.49 \mathrm{SE}$; the average night temperature was $23.9^{\circ} \mathrm{C} \pm 0.31 \mathrm{SE}$. The average day relative humidity $(\mathrm{RH})$ was $61.0 \%$ $\pm 1.27 \mathrm{SE}$; the average night $\mathrm{RH}$ was $83.8 \% \pm 0.91 \mathrm{SE}$.

Dormant, 2-year-old red and jack pine nursery seedlings were lifted 18 November 1993 and transplanted into Deepot cones (conical tubes; width $6.4 \mathrm{~cm} \times$ depth 25.4 $\mathrm{cm}$; Stuewe \& Sons Inc., Corvallis, OR) in a soil $\mathrm{mix}$ ( $\mathrm{vol} / \mathrm{vol})$ as described above. Red pine seedlings had a mean stem height of $12.8 \mathrm{~cm} \pm 0.13 \mathrm{SE}$ and jack pine had a mean stem height of $24.5 \mathrm{~cm} \pm 0.33 \mathrm{SE}$ at the time transplanted. Artificial light supplemented natural light as above (maximum recorded ambient greenhouse photon flux density was $920 \mu \mathrm{E} \mathrm{s}^{-1} \mathrm{~m}^{-2}$ ) to provide a 16-h photoperiod. Seedlings were watered to field capacity every 3 days. The average greenhouse day temperature was approximately $25^{\circ} \mathrm{C}$; the average night temperature was approximately $18^{\circ} \mathrm{C}$. The average night RH was approximately $38 \%$. One week after bud break the trees were watered to field capacity with $2.0 \mathrm{cc}$ of Peters Acid Greening soluble fertilizer (17:6:6 N/P/K; Scotts Co., Allentown, PA) per liter.

Inoculation of nonwounded 1-year-old seedlings with conidia. Conidial inoculum was produced for five monoconidial isolates of each morphotype collected from various pine species and locations in the north central United States (Table 1). De- 
barked red pine twig sections were placed on $1.5 \%$ water agar (WA; Difco, Detroit, MI) plates inoculated with colonized WA plugs. Plates were incubated for 5 weeks at ambient laboratory temperature (approximately $24^{\circ} \mathrm{C}$ ) and light. Twigs on which pycnidia developed were scraped with a scalpel and washed with sterile, distilled water to release conidia. For controls, twigs on uninoculated WA plates were scraped with a scalpel and washed in the same manner. The resulting suspensions were filtered through two layers of sterile cheesecloth. Conidial concentrations were adjusted to approximately $5 \times 10^{3}$ conidia per $\mathrm{ml}$ in sterile, distilled water with a hemacytometer, and stored at $-20^{\circ} \mathrm{C}$ for 1 week. Conidial suspensions were kept on ice to prevent spore germination prior to inoculations.

Elongating, asymptomatic shoots were inoculated in the greenhouse approximately 4 weeks after planting. Seedlings were held upside down, and all but the apical $2 \mathrm{~cm}$ shielded with plastic. The shoot apex was then sprayed (with an atomizer) with $0.4 \mathrm{ml}$ of conidial suspension. Seedlings were then enclosed in clear plastic bags sealed to the pot rim for 4 days to maintain high RH. A sample of each conidial suspension also was placed on $2 \%$ WA in petri plates immediately before inoculations. Plates were sealed with Parafilm and incubated in the dark at $25^{\circ} \mathrm{C}$. Percent germination of 100 conidia was determined for each isolate after $12 \mathrm{~h}$. The average percent germination for all isolates was $68 \% \pm 3.8 \mathrm{SE}$.

A randomized complete block design was used with five blocks, each with 110

Table 1. Origin of Sphaeropsis sapinea isolates

\begin{tabular}{|c|c|c|c|}
\hline $\begin{array}{l}\text { Iso- } \\
\text { late }^{\text {a }}\end{array}$ & $\begin{array}{l}\text { Isolate } \\
\text { no. }{ }^{\text {b }}\end{array}$ & $\begin{array}{l}\text { Pine } \\
\text { host }^{c}\end{array}$ & Geographic origin \\
\hline A1 & 411 & Red & Clearwater Co., MN \\
\hline A2 & 128 & Red & Grant Co., WI \\
\hline A3 & 239 & Red & Douglas Co., WI \\
\hline A4 & 92-14-A & Austrian & Dane Co., WI \\
\hline A5 & 92-19-A & Red & Wood Co., WI \\
\hline A6 & $92-43-A$ & Scot's & Waushara Co., WI \\
\hline A7 & $92-46-\mathrm{A}$ & Austrian & La Crosse Co., WI \\
\hline A8 & $92-60-A$ & Red & Sheboygan Co., WI \\
\hline A9 & $92-66-A$ & Scot's & Kalamazoo Co., MI \\
\hline B1 & 124 & Jack & Jackson Co., WI \\
\hline B2 & 215 & Red & Douglas Co., WI \\
\hline B3 & 113 & Jack & Gogebic Co., MI \\
\hline B4 & 457 & Red & Jackson Co., WI \\
\hline B5 & 459 & Jack & Douglas Co., WI \\
\hline B6 & 462 & Red & Clearwater Co., MN \\
\hline B7 & 474 & Red & Wadena Co., MN \\
\hline B8 & 92-9-A & Jack & Wood Co., WI \\
\hline
\end{tabular}

${ }^{a}$ Morphotype and isolate number. All isolates were used in the wound-inoculation experiment. Isolates A1, A2, A3, A7, A9, B1, B2, $\mathrm{B} 5, \mathrm{~B} 6$, and $\mathrm{B} 8$ were used in the nonwounded-inoculation experiment.

${ }^{b}$ Culture collection numbers of M. A. Palmer (3-digit number) or G. R. Stanosz (92-xx-A).

${ }^{c}$ Host collected on include red (Pinus resinosa), Austrian ( $P$. nigra), Scot's ( $P$. sylvestris), and jack (P. banksiana) pines. red and 110 jack pine seedlings $(1,100$ seedlings total). Ten seedlings per treatment combination (tree species and isolate) and 10 control seedlings of each tree species were used in each block. All treatments were assigned randomly.

Eight weeks after inoculation, the presence or absence of necrotic needles, crooked shoot tips, cankers, and dead shoot tips (apical $2 \mathrm{~cm}$ ) was observed and recorded. The percentage of necrotic needles was estimated for each seedling. After needles were removed, 5-cm-long shoot sections were surface disinfected for $10 \mathrm{~s}$ in $95 \%$ ethanol followed by $4 \mathrm{~min}$ in $1.05 \% \mathrm{NaOCl}$ solution with 2 drops of Tween 80 (Fisher Scientific Co., Toronto, Ontario) per liter. The apical 2-cm section was aseptically cut from the 5-cm-long shoot section, transferred to a $2.0 \%$ WA slant, and incubated for 10 weeks at ambient laboratory temperature (approximately $24^{\circ} \mathrm{C}$ ) and light. The presence of $S$. sapinea in incubated shoot sections was determined by examining the resulting mycelia, pycnidia, and conidia.

Inoculation of wounded 2-year-old seedlings with mycelium. The elongating, asymptomatic terminal shoot of each seedling was inoculated in the greenhouse approximately 6 weeks after transplanting. On each shoot, a single wound (approximately $3 \mathrm{~mm} \times 1.5 \mathrm{~mm}$ ) was made by removing a needle fascicle (by a scalpel cut flush to the stem) approximately $2 \mathrm{~cm}$ distal to the shoot apex. A plug, $4 \mathrm{~mm}$ in diameter, was cut from the margin of an actively growing culture on $1.5 \% \mathrm{WA}$ and placed fungus-side-down on the wound. Parafilm was wrapped around the shoot for 6 days. Wounded and nonwounded controls also were included. A noncolonized WA plug was applied to wounded controls. Nine A and eight B monoconidial isolates

Table 2. Incidence of symptoms for nonwounded red (Pinus resinosa) and jack ( $P$. banksiana) pines inoculated with A and B morphotype isolates of Sphaeropsis sapinea

\begin{tabular}{lccc}
\hline & \multicolumn{3}{c}{ Percent (range) with symptoms } \\
\cline { 2 - 4 } Morphotype & Red pine & Jack pine & $\boldsymbol{P}^{\mathbf{a}}$ \\
\hline A & $97(92-100)^{\mathrm{b}}$ & $42(22-56)$ & $<0.001$ \\
$\mathrm{~B}$ & $18(14-24)$ & $6(4-10)$ & 0.059 \\
$P^{\mathrm{c}}$ & $<0.001$ & $<0.001$ & \\
\hline
\end{tabular}

a Probability that there is no difference between hosts within a row, based on chi-square tests. Probabilities are based on the number with symptoms.

${ }^{b}$ Mean percentage (range) of seedlings with symptoms (needle necrosis or dead shoot tips) on nonwounded seedlings 8 weeks after inoculation with conidia of A and B morphotype isolates of $S$. sapinea. Values are combined means of 5 separate blocks each having 10 seedlings per treatment with 5 isolates per morphotype.

${ }^{c}$ Probability that there is no difference between morphotypes within a column, based on chisquare tests. Probabilities are based on the number with symptoms. were used (Table 1). Ten seedlings per treatment combination (tree species and isolate) and 10 wounded and nonwounded control seedlings of each tree species were used in each of two separate trials separated by 2 weeks (760 seedlings total). All treatments were assigned randomly.

Four weeks after inoculation, the presence or absence of necrotic needles, crooked shoot tips, and dead shoot tips (apical $2 \mathrm{~cm}$ ) was observed and recorded. The distances below the inoculation site at which necrotic needles and cankers were present were measured. After needles were removed, 22-cm-long shoot sections were surface disinfected as described above. Cross sections, $1 \mathrm{~cm}$ long, centered at 0,3 , $6,9,12$, and $15 \mathrm{~cm}$ from the inoculation site, were aseptically cut. Each of the six cross sections was transferred to a $2.0 \%$ WA slant and incubated for 10 weeks at ambient laboratory temperature (approximately $24^{\circ} \mathrm{C}$ ) and light. The presence of $S$. sapinea in incubated shoot sections was determined as described above.

Statistical analyses. Quantitative data (percentages of crowns with necrotic needles and distances below the inoculation site at which necrotic needles were present) were analyzed by three-factor analyses of variance with all interactions. Factors used as main effects were tree species, isolate, and block or trial. The responses by morphotype (for percentages of crowns with necrotic needles and distances below the inoculation site at which necrotic needles were present) were compared by a contrast. Simple linear regression analyses were used to examine relationships between quantitative variables (mean distance from the inoculation site at which necrotic needles and cankers were observed, and distance of recovery from the inoculation site). Chi-square goodness-offit analyses were used to analyze frequency data (numbers of seedlings with symptoms, with dead shoot tips, and in which $S$. sapinea was recovered). Three-factor analyses of variance (with general linear model procedure) and linear regression analyses were performed with the Minitab for Windows program (Minitab Inc., State College, PA, release 10.2). Chi-square goodness-of-fit analyses were performed with the Statgraphics program (STSC Inc., Rockville, MD, release 5.1).

\section{RESULTS}

Inoculation of nonwounded 1-year-old seedlings with conidia. Symptoms on both pine species were similar to symptoms reported for field and nursery studies. These included dead tips, crooked shoot tips, necrotic needles, and stem cankers. The first symptoms present after 5 days were necrotic needles scattered throughout the apical $2 \mathrm{~cm}$.

Inoculations with either A or B isolates resulted in symptom development on both nonwounded hosts (Table 2). However, A 
isolates caused greater mean incidence of disease than B isolates $(P<0.001)$ on both red $(97 \% \pm 1.4 \mathrm{SE}$ versus $18 \% \pm 1.7 \mathrm{SE}$ of the seedlings exhibited symptoms) and jack pines $(42 \% \pm 6.1 \mathrm{SE}$ versus $6 \% \pm 1.2$ SE exhibited symptoms). Isolates of both morphotype had greater incidence of disease in red pine than in jack pine $(P<$ 0.001 for A morphotype; $P=0.059$ for $\mathrm{B}$ morphotype).

The three-factor analysis of variance of the percentage of the crown with necrotic needles indicated significant effect of the isolate used $(P<0.001)$ and tree species $(P$ $<0.001)$, but not of block $(P=0.108)$. There also was interaction between isolate used and tree species $(P<0.001)$, indicating that the two hosts responded differently to the different isolates. Because the analysis indicated no significant effect of block and no interaction of block with isolate used $(P=0.456)$ or tree species $(P=$ $0.958)$, the data for the five blocks were combined (Table 3 ).

A isolates caused greater percentages of necrotic needles than $B$ isolates on both hosts, based on contrast analysis (Table 3; $P<0.001)$. When inoculated with A isolates, red pine had a greater percentage of necrotic needles $(P<0.001)$ on average than jack pine $(38.3 \% \pm 7.1 \mathrm{SE}$ versus $17.4 \% \pm 2.5 \mathrm{SE})$. When inoculated with $\mathrm{B}$ isolates, the percentages of necrotic needles were low and not statistically different $(P=0.218)$ for red pine and jack pine $(5.2 \% \pm 1.0 \mathrm{SE}$ versus $2.2 \% \pm 1.2 \mathrm{SE})$.

Inoculations with A isolates also caused more dead shoot tips than inoculations with $\mathrm{B}$ isolates on both hosts, based on chi-square analyses $(P<0.001)$. Red pine had greater shoot-tip mortality on average than jack pine $(P<0.001)$ when inoculated with $\mathrm{A}$ isolates $(45 \% \pm 8.3 \mathrm{SE}$ versus $18 \% \pm 2.3 \mathrm{SE}$ with dead tips). There was little shoot-tip mortality observed on either red or jack pine inoculated with $\mathrm{B}$ isolates $(5 \% \pm 1.0 \mathrm{SE}$ versus $2 \% \pm 1.2 \mathrm{SE}$ with dead tips; $P=0.061$ ).

Table 3. Symptom severity for nonwounded red (Pinus resinosa) and jack ( $P$. banksiana) pines inoculated with A and B morphotype isolates of Sphaeropsis sapinea

\begin{tabular}{|c|c|c|c|}
\hline \multirow{2}{*}{$\begin{array}{l}\text { Morph- } \\
\text { otype }\end{array}$} & \multicolumn{3}{|c|}{$\begin{array}{l}\text { Percent (range) crown with } \\
\text { necrotic needles }\end{array}$} \\
\hline & Red pine & Jack pine & $P^{\mathbf{a}}$ \\
\hline 17 & $38.3(1$ & $17.4(\mathrm{C}$ & $<0.0$ \\
\hline B & $5.2(2.4-7.8)$ & $2.2(0.1-6.1)$ & 0.218 \\
\hline$P^{\mathrm{c}}$ & $<0.001$ & $<0.001$ & \\
\hline
\end{tabular}

a Probability that there is no difference between hosts within a row, based on a contrast.

b Mean percentage (range) of crown with necrotic needles on nonwounded seedlings 8 weeks after inoculation with conidia of $A$ and B morphotype isolates of $S$. sapinea. Values are combined means of 5 separate blocks each having 10 seedlings per treatment with 5 isolates per morphotype.

${ }^{c}$ Probability that there is no difference between morphotypes within a column, based on a contrast.
Sphaeropsis sapinea was recovered from stems of both hosts inoculated with spores of either morphotype even when symptoms were not apparent. The average recovery from red pine was $67 \% \pm 4.2 \mathrm{SE}$ for $\mathrm{A}$ isolates and $66 \% \pm 3.8 \mathrm{SE}$ for B isolates $(P$ $=0.826)$. The average recovery from jack pine was $49 \% \pm 5.8 \mathrm{SE}$ for $\mathrm{A}$ isolates and $45 \% \pm 4.6 \mathrm{SE}$ for B isolates $(P=0.361)$. Sphaeropsis sapinea was recovered more often from red pine than from jack pine for both the A morphotype $(P=0.010)$ and $\mathrm{B}$ morphotype $(P=0.001)$.

Inoculation of wounded 2-year-old seedlings with mycelium. Symptoms on both red and jack pine included dead tips, crooked shoot tips, necrotic needles, and stem cankers, similar to symptoms reported for seedlings in field and nursery studies. The first symptoms present after 6 days included both necrotic needles and stem cankers at the wound sites. Development of similar symptoms occurred after inoculation with either A or B isolates, but the incidence (Table 4) and severity (Table 5) of symptoms differed.

On wounded pines, A isolates caused greater mean incidence of disease than $\mathrm{B}$ isolates $(P<0.001)$ on both red $(100 \% \pm$ $0.0 \mathrm{SE}$ versus $21 \% \pm 3.6 \mathrm{SE}$ of the seedlings exhibited symptoms) and jack pines $(99 \% \pm 0.6 \mathrm{SE}$ versus $53 \% \pm 7.0 \mathrm{SE}$ with symptoms). Isolates of the A morphotype had similar incidence of disease in both hosts $(P=0.958)$ and the B morphotype had greater incidence of disease in jack pine than in red pine $(P<0.001)$. There were no differences in the incidence of disease among red pine seedlings inoculated with either A $(P=1.000)$ or B $(P=0.266)$ isolates nor among jack pine seedlings inoculated with A isolates $(P=0.429)$. However, there was greater variation in the in-

Table 4. Incidence of symptoms for woundinoculated red (Pinus resinosa) and jack ( $P$. banksiana) pines inoculated with A and B morphotype isolates of Sphaeropsis sapinea

\begin{tabular}{lccc}
\hline \multirow{2}{*}{$\begin{array}{l}\text { Morpho- } \\
\text { type }\end{array}$} & \multicolumn{3}{c}{ Percent (range) with symptoms } \\
\cline { 2 - 4 } & Red pine & Jack pine & $\boldsymbol{P}^{\mathbf{a}}$ \\
\hline $\mathrm{A}$ & $100($ all 100) & $99(95-100)$ & 0.958 \\
$\mathrm{~B}$ & $21(10-40)$ & $53(20-80)$ & $<0.001$ \\
$P^{\mathrm{c}}$ & $<0.001$ & $<0.001$ & \\
\hline
\end{tabular}

a Probability that there is no difference between hosts within a row, based on chi-square tests. Probabilities are based on the number with symptoms.

${ }^{b}$ Mean percentage (range) of seedlings with symptoms (needle necrosis or dead shoot tips) on wounded seedlings 4 weeks after inoculation with agar plugs colonized by A and B morphotype isolates of $S$. sapinea. Values are combined means of 2 separate trials each having 10 seedlings per treatment with 9 isolates per A morphotype and 8 isolates per B morphotype.

${ }^{c}$ Probability that there is no difference between morphotypes within a column, based on chisquare tests. Probabilities are based on the number with symptoms. cidence of symptoms for B isolates on jack pine than on red pine. Significant differences in the incidence of disease were observed among jack pine seedlings inoculated with $\mathrm{B}$ isolates $(P=0.002)$ based on chi-square goodness-of-fit analysis.

Three-factor analysis of variance of the distance from the inoculation site at which necrotic needles were observed indicated significant effect of the isolate used $(P<$ $0.001)$, but not of tree species $(P=0.375)$. However, there was interaction between isolate used and tree species $(P<0.001)$, indicating that the two hosts responded differently to the different isolates. Because the analysis also indicated significant effect of trial $(P<0.001)$ and significant interaction of isolate used and trial $(P=$ $0.004)$, the data for the two trials are presented separately (Table 5).

The distance from the inoculation site at which necrotic needles were observed differed by morphotype on both host species and in both trials, based on contrast analysis (Table 5; $P<0.001$ ). On red pine, A isolates caused necrotic needles at greater distances from the inoculation sites than $\mathrm{B}$ isolates $(6.6 \mathrm{~cm} \pm 0.3 \mathrm{SE}$ versus $0.4 \pm 0.1$ SE $\mathrm{cm}$ on average in trial $1 ; 8.8 \mathrm{~cm} \pm 0.3$ SE versus $0.1 \pm 0.1 \mathrm{SE} \mathrm{cm}$ on average in trial 2). On jack pine, A isolates also caused necrotic needles at greater distances from the inoculation sites than B isolates, but differences were less extreme $(5.8 \mathrm{~cm}$ $\pm 0.3 \mathrm{SE}$ versus $1.7 \pm 0.4 \mathrm{SE} \mathrm{cm}$ on average in trial $1 ; 6.5 \mathrm{~cm} \pm 0.3 \mathrm{SE}$ versus $3.0 \pm$ $0.4 \mathrm{SE} \mathrm{cm}$ on average in trial 2). The B morphotype isolates were more aggressive on jack pine than on red pine (Table 5). There also was greater variation in severity of symptoms for B isolates on jack pine

Table 5. Symptom severity for wound-inoculated red (Pinus resinosa) and jack (P. banksiana) pines inoculated with A and B morphotype isolates of Sphaeropsis sapinea

\begin{tabular}{cccc}
\hline & \multicolumn{2}{c}{$\begin{array}{c}\text { Distance (range) from site } \\
\text { of inoculation }(\mathbf{c m})\end{array}$} & \\
\cline { 3 - 3 } $\begin{array}{l}\text { Morph- } \\
\text { otype }\end{array}$ & Red pine & Jack pine & $\boldsymbol{P}^{\mathbf{a}}$ \\
\hline Trial 1 & & & \\
A & $6.6(5.2-7.9)^{\mathrm{b}}$ & $5.8(4.4-7.6)$ & 0.059 \\
B & $0.4(0.0-0.6)$ & $1.7(0.5-4.5)$ & 0.001 \\
$P^{\mathrm{c}}$ & $<0.001$ & $<0.001$ & \\
Trial 2 & & & \\
A & $8.8(7.4-10.2)^{\mathrm{b}}$ & $6.5(4.1-8.9)$ & $<0.001$ \\
$\mathrm{~B}$ & $0.1(0.0-0.6)$ & $3.0(0.4-6.2)$ & $<0.001$ \\
$P^{\mathrm{c}}$ & $<0.001$ & $<0.001$ & \\
\hline
\end{tabular}

a Probability that there is no difference between hosts within a row, based on a contrast.

${ }^{b}$ Mean distance (range) from the inoculation site at which necrotic needles were observed on wounded seedlings 4 weeks after inoculation with agar plugs colonized by $\mathrm{A}$ and $\mathrm{B}$ morphotype isolates of $S$. sapinea. Values are means of 2 separate trials each having 10 seedlings per treatment with 9 isolates per A morphotype and 8 isolates per B morphotype.

${ }^{c}$ Probability that there is no difference between morphotypes within a column, based on a contrast. 
than on red pine, based on SE and ranges. For red pine, there was consistent separation of morphotype isolates in both trials, but for jack pine overlap of the ranges between A and B morphotype isolates occurred in both trials. The mean distance from the inoculation site at which necrotic needles were observed on either host was positively correlated with the mean distance of cankers $(r=0.98, P<0.001)$.

More dead shoot tips were observed on seedlings of both hosts inoculated with A isolates than B isolates, based on chisquare analyses $(P<0.001)$. Red pine had frequencies of shoot-tip mortality on average similar to those of jack pine $(P=$ 0.791) when inoculated with $A$ isolates $(99 \% \pm 0.7 \mathrm{SE}$ versus $96 \% \pm 1.4 \mathrm{SE}$ with dead tips). There was less shoot-tip mortality observed on red pine than on jack pine inoculated with B isolates $(4 \% \pm 1.4$ SE versus $39 \% \pm 8.5$ SE with dead tips; $P$ $<0.001)$.

Sphaeropsis sapinea was frequently recovered from both hosts inoculated with either morphotype even when symptoms were not apparent. It was successfully recovered at the inoculation point in $100 \% \pm$ $0.0 \mathrm{SE}$ of the A isolate treatments for both hosts and in $93 \% \pm 3.7 \mathrm{SE}$ for red pine and $93 \% \pm 2.5 \mathrm{SE}$ for jack pine of the B isolate treatments. However, A isolates were recovered farther from the inoculation site than $\mathrm{B}$ isolates $(P<0.001)$ for both red $(6.8 \mathrm{~cm} \pm 0.2 \mathrm{SE}$ versus $0.1 \mathrm{~cm} \pm 0.1 \mathrm{SE}$ on average) and jack pine $(5.6 \mathrm{~cm} \pm 0.4 \mathrm{SE}$ versus $2.0 \mathrm{~cm} \pm 0.4 \mathrm{SE}$ on average). Symptom development, expressed as mean distance below the inoculation site with necrotic needles, was positively correlated with distance of recovery $(r=0.94, P<$ 0.001).

\section{DISCUSSION}

These results demonstrate the pathological significance of differentiating S. sapinea isolates from the north central United States as either A or B morphotype. Although isolates of each morphotype can infect nonwounded tissues, differences in aggressiveness, at least on red pine, were apparent. This indicates the need to obtain and characterize isolates of the pathogen encountered in field studies, and to use isolates of known morphotype in further research.

Previous reports conflict on the necessity of wounds for infection by $S$. sapinea $(4,6,10,14)$. However, infection through stomata of young needles $(3,13)$ and direct penetration of young intact shoots (5) has been demonstrated for isolates of unknown morphotype. Because isolates of B type were collected only from wounded tissue $(12,22)$ it was proposed that they may be opportunistic colonizers of wounded or weakened host tissues. It also has been suggested that the differing conclusions concerning the necessity for wounds, stated previously in the literature, may have re- sulted from observations of different morphotypes (11).

Only one previous study has been conducted on the differences between isolates of known morphotypes in their requirements for host penetration (12). It was reported that a single representative $\mathrm{A}$ isolate infected nonwounded young shoots and a single representative $\mathrm{B}$ isolate required wounds for penetration. In this study, some symptoms developed on young, uninjured tissue of both red and jack pines inoculated with conidial suspensions of all isolates of either morphotype. The recovery of $S$. sapinea from nonwounded inoculated seedlings was similar for either morphotype on the same host. This indicates that both morphotypes can penetrate their hosts without wounding. Consistent with previous suggestions that $S$. sapinea inhabits asymptomatic stems (17), recovery of B isolates was more frequent than the occurrence of disease symptoms. The considerable differences between the two morphotypes in symptom incidence and severity observed in this study may explain previous conflicting reports on the necessity of wounds for infection by $S$. sapinea.

Although isolates of both morphotypes can infect young, uninjured tissue of both red and jack pines in the greenhouse, some differences in aggressiveness were found between morphotypes, on both hosts in both experiments. Variations in aggressiveness have been observed among different isolates of $S$. sapinea $(15,18)$, but these earlier studies did not differentiate A and B morphotypes. In the present study, in both experiments, red and jack pines were more affected in both disease incidence and severity by $\mathrm{A}$ isolates than by $\mathrm{B}$ isolates on average. This confirms results from a preliminary study with two A and two B isolates (1). Differences were much more pronounced for red pine than jack pine in the wound-inoculation experiment in which all $\mathrm{A}$ isolates were more aggressive (resulted in necrotic needles and recoveries of $S$. sapinea farther from the inoculation site) than all B isolates. The woundinoculation technique used in this study provides a reproducible method for comparing the aggressiveness of $\mathrm{A}$ and $\mathrm{B}$ isolates from the north central United States on red pine. It was not reliable for determining differences in aggressiveness among isolates of these two morphotypes on jack pine. The large difference in symptom severity induced following wound-inoculation of red pine seedlings also allows differentiation of isolate morphotype based on the response of this host. With the wound-inoculation method of this study, the host range and aggressiveness of both morphotypes can be examined under controlled conditions. Preliminary results also suggest that similar techniques result in similar expression of differences in aggressiveness between morphotypes under field conditions (2).
At present, the complete host and geographic ranges of the two morphotypes are unclear. Differences in aggressiveness have been described for unidentified morphotypes on various hosts $(8,15,21)$. Jack pine was suggested as the preferred host of B isolates in the north central United States (11). Although A isolates were aggressive on both hosts in our study, B isolates were only aggressive on wounded jack pines. There was little colonization or damage of red pines by $B$ isolates in the woundinoculation experiment. This supports the suggestion that jack pine may be a better host for B isolates than red pine. Isolates of $\mathrm{B}$ type have only been recovered from red and jack pines in the north central United States, whereas A isolates are reported to occur on various hosts worldwide (20). The known host range of $\mathrm{B}$ morphotypes may increase with further studies.

Proper identification of the S. sapinea morphotype(s) in a given plantation or area may help estimate risk of damage from the disease. Because significant differences in aggressiveness occur between morphotypes on red pine, identifying the morphotype(s) in an area may be important before management strategies are implemented to control the disease on red pine in the north central United States. If only B isolates are found in an area, management to control this disease on red pine may be unwarranted, though the level of risk and need for management activities to control the disease under field conditions where only $B$ types are found on red pine are unknown.

\section{ACKNOWLEDGMENTS}

We thank P. Manion and J. Buck for presubmission reviews, and E. G. Kuhlman and two anonymous reviewers for their many helpful suggestions. We also thank M. Clayton for statistical advice, M. Palmer for cultures, the Wisconsin Department of Natural Resources for seedlings, and D. Smith, M. Guthmiller, G. Sandhu, J. Stanosz, L. Covert, and S. Birren for technical assistance. Partial financial support was provided by the USDA (Hatch).

\section{LITERATURE CITED}

1. Blodgett, J. T., and Stanosz, G. R. 1993. Morphotype and water stress effects on disease development by Sphaeropsis sapinea on red pine. (Abstr.) Phytopathology 83:1352.

2. Blodgett, J. T., and Stanosz, G. R. 1995 Sphaeropsis sapinea and host water stress in a red pine plantation in central Wisconsin. (Abstr.) Phytopathology 85:1044.

3. Brookhouser, L. W., and Peterson, G. W. 1971. Infection of Austrian, Scots, and ponderosa pine by Diplodia pinea. Phytopathology 61:409-414.

4. Chou, C. K. S. 1976. A shoot dieback in Pinus radiata caused by Diplodia pinea. II. Inoculation studies. N.Z. J. For. Sci. 6:409420.

5. Chou, C. K. S. 1978. Penetration of young stems of Pinus radiata by Diplodia pinea. Physiol. Plant Pathol. 12:189-192.

6. Chou, C. K. S., and MacKenzie, M. 1988. Effect of pruning intensity and season on Diplodia pinea infection of Pinus radiata stem through pruning wounds. Eur. J. For. Pathol. 18:437-444. 
7. Farr, D. F., Bills, G. F., Chamuris, G. P., and Rossman, A. Y. 1989. Fungi on Plants and Plant Products in the United States. American Phytopathological Society, St. Paul, MN.

8. Gibson, I. A. S. 1979. Diseases of Forest Trees Widely Planted as Exotics in the Tropic and Southern Hemisphere. Part II. The Genus Pinus. Commonw. Mycol. Inst., Kew, England.

9. Hawksworth, D. L., Kirk, P. M., Sutton, B. C., and Pegler, D. N. 1995. Ainsworth and Bisby's Dictionary of the Fungi, 8th ed. Int. Mycol. Inst., Egham, England.

10. Nicholls, T. H., and Ostry, M. E. 1990. Sphaeropsis sapinea cankers on stressed red and jack pines in Minnesota and Wisconsin. Plant Dis. 74:54-56.

11. Palmer, M. A. 1991. Isolate types of Sphaeropsis sapinea associated with main stem cankers and top-kill of Pinus resinosa in Minnesota and Wisconsin. Plant Dis. 75:507-510.

12. Palmer, M. A., Stewart, E. L., and Wingfield,
M. J. 1987. Variation among isolates of Sphaeropsis sapinea in the north central United States. Phytopathology 77:944-948.

13. Peterson, G. W. 1977. Infection, epidemiology, and control of Diplodia blight of Austrian, ponderosa, and Scots pine. Phytopathology 67:511-514

14. Purnell, H. M. 1957. Shoot blight of Pinus radiata Don caused by Diplodia pinea (Desmaz.) Kickx. For. Comm. Vic. Bull: 5.

15. Rees, A. A., and Webber, J. F. 1988. Pathogenicity of Sphaeropsis sapinea to seed, seedlings and saplings of some Central American pines. Trans. Br. Mycol. Soc. 91:273277.

16. Smith, D. R., and Stanosz, G. R. 1995. Confirmation of two distinct populations of Sphaeropsis sapinea in the north central United States using RAPDs. Phytopathology 85:699-704.

17. Stanosz, G. R., Smith, D. R., Guthmiller, M. R., and Stanosz, J. C. 1995. Persistence of
Sphaeropsis sapinea on or in asymptomatic stems of red pine nursery seedlings. (Abstr.) Phytopathology 85:1196.

18. Swart, W. J., Wingfield, M. J., Palmer, M. A., and Blanchette, R. A. 1991. Variation among South African isolates of Sphaeropsis sapinea. Phytopathology 81:489-493.

19. Swart, W. J., Wingfield, M. J., and van Wyk, P. 1993. Variation in conidial morphology among geographic isolates of Sphaeropsis sapinea. Mycol. Res. 97:832-838.

20. Wang, C.-G., Blanchette, R. A., Jackson, W. A., and Palmer, M. A. 1985. Differences in conidial morphology among isolates of Sphaeropsis sapinea. Plant Dis. 69:838-841.

21. Waterman, A. M. 1943. Diplodia pinea, the cause of a disease of hard pines. Phytopathology 33:1018-1031.

22. Wingfield, M. J., and Palmer, M. A. 1983. Diplodia pinea associated with insect damage on pines in Minnesota and Wisconsin. Page 249 in: Int. Congr. Pathol., 4th. 